\title{
Occupational risks of sinonasal cancer in Denmark
}

\author{
J H OLSEN
}

From the Danish Cancer Registry, Institute of Cancer Epidemiology, Danish Cancer Society, Copenhagen, Denmark

ABSTRACT A new comprehensive data linkage system for the detailed investigation of occupational cancer has been established in the Danish Cancer Registry, providing employment histories back to 1964. All 382 cases of cancers of the sinonasal cavities diagnosed between 1970 and 1984 and kept on file in this data linkage system were analysed using standardised proportional incidence ratios (SPIR) to screen for industrial high risk areas for these malignancies in Denmark. Excess risks were confirmed among men and women employed in the manufacture of footwear and other leather products and of wooden furniture. No risk significantly above expectancy was observed among wood workers outside the furniture making industry. Excess risks were also seen among men in all areas of basic metal industries (SPIR $=184-562$ ) and in a subset of workers in industries producing metal containers (SPIR $=329-600$ ). Most unexpected were raised risks among employees of both sexes in making cocoa, chocolate, and sugar confectionery (SPIR = 535 for men and 860 for women); these, in combination with the observed risks among female employees in canning and preserving fruits and vegetables $($ SPIR $=778)$ and in farming $($ SPIR $=735)$ may point to a common aetiology. The obscuring effect of mass significance may, however, be another explanation. The new associations discovered in this large scale linkage study must therefore await further confirmation.

Several occupations and industrial exposures have been associated with excess risks of cancers of the nasal cavity and paranasal sinuses. Owing to the rarity of these tumours in the population at large, identification of high risk groups has frequently been based on the recognition of a few cases with an attendant high incidence rate in the exposed group'; however, substantial knowledge of risk factors in the working environment has accumulated over the past 10-20 years.

A firm association between employment in the furniture making industry and the occurrence of nasal adenocarcinomas has been shown in Europe and in North America. ${ }^{2-6}$ Woodworkers outside the furniture making industry also seem to be at risk. ${ }^{7}$ It is well established that workers engaged in nickel refining have an excess risk of developing cancers of the respiratory system, including cancers of the nasal cavity and paranasal sinuses. ${ }^{8}$ Raised risks have also been reported for workers exposed to chromium compounds, ${ }^{79}$ radium, ${ }^{10}$ mustard gas, ${ }^{11}$ and cutting oils, ${ }^{12}$ and for workers engaged in making paint, lacquer, and glue. ${ }^{73}$ Relative risks well in excess of tenfold have been reported in the boot and shoe manufacturing industry in England and Italy, ${ }^{314} 15$ and

Accepted 11 May 1987 an increased risk of cancer of the ethmoid sinus has been associated with the manufacture of isopropyl alcohol by the strong acid process. ${ }^{16}{ }^{17}$ Other studies have shown an association between risk of nasal cancer and employment in the textile industry ${ }^{18} 19$ and in the petroleum and chemical industries..$^{20-22}$ Recently, exposure to formaldehyde has been linked with cancers of the nasal cavity and paranasal sinuses. ${ }^{132324}$

The present paper reports on record linkage of occupational histories and tumour registry information on all cases of sinonasal cancer in Denmark, 1970-84, with special attention to associations that have not been previously reported.

\section{Material and methods}

The occupational histories of all patients with a malignancy of the sinonasal cavities has been assessed by a comprehensive linkage of all cases of cancer, 1970-84, kept on file in the Danish Cancer Registry, with the job histories of all employees in the country on file in the Supplementary Pension Fund. The linked Cancer Registry-Supplementary Pension Fund data file is described in detail elsewhere. ${ }^{25}$

The Danish Cancer Registry, which is a population based tumour registry founded in 1942, receives reports on all cancers newly diagnosed in the coun- 
Table 1 Proportion of cancer cases recovered from the files of the Supplementary Pension Fund (SPF), see text

\begin{tabular}{lrlrrr}
\hline Cancer (ICD-7) & \multicolumn{2}{c}{ SPF membership No (\%) } & \multicolumn{2}{c}{ No SPF membership No (\%)* } & All patients No (\%) \\
\hline $160 \cdot 0,160 \cdot 2-9 \dagger$ & 164223 & $(71)$ & $159(29)$ & 541 & $(100)$ \\
All other diagnoses & 164605 & $(62)$ & $101086(38)$ & $265309(100)$ \\
Total & $101245(38)$ & $265850(100)$ \\
\hline
\end{tabular}

*Self employed, housewives, students, unemployed, etc.

†Lymphomas of the nasal cavities not included.

try. ${ }^{26}$ The validity of the registration has been satisfactory; a system of multiple sources of notification of tumours (clinical departments, pathology departments, departments of forensic medicine, and death certificates) yields a high degree of completeness. ${ }^{27}{ }^{28} \mathrm{At}$ the time this study was conducted, cancer registration was not yet complete for the years 1983 and 1984, and deficits of approximately $6 \%$ and $32 \%$ of cases, respectively, are being processed or await notification. Use of the personal identity number, introduced by law in 1968, reduces the risk of duplicate registrations of the same tumour. The classification used by the tumour registry is that of the 7th revision of the International Classification of Diseases (ICD-7). ${ }^{29}$

The Danish Supplementary Pension Fund, which covers all employees in the country, was established in 1964. The pension scheme is compulsory for wage earners aged 16-66 and the pension supplement is financed by monthly contributions from the wage earners themselves and from their employers. Both contributions are paid quarterly by the employers to a nationwide central fund, which retains all information on contributors, pensioners, and those who have died, including identity numbers of employees, names and addresses of employing companies, and codes for the industrial categories to which the companies belong. The latter is a five digit, hierarchically formed number that corresponds closely to the International Standard Industrial Classification of All Economic Activities. ${ }^{30}$

Using ICD-7 codes $160 \cdot 0$ and $160 \cdot 2-160 \cdot 9$, all cases of cancer of the nasal cavity and paranasal sinuses were sorted out from the linked Cancer Registry Supplementary Pension Fund data set (table 1). In $71 \%$ of cases the patient had been an employee and the case report could be complemented by a complete occupational history since April 1964 (table 2). For the remaining $29 \%$ (mostly women), no information on employment could be obtained; these people had been housewives, self-employed, or students during the period covered by the pension fund.

\section{ANALYSIS}

The occupation held longest by the patient was chosen as the risk factor. Since only cases of cancer were included in the study, in the absence of population denominators, a proportional incidence analysis was performed. The risk of sinonasal cancer associated
Table 2 Information from the Cancer Registry and the Supplementary Pension Fund included in the linked data file

\begin{tabular}{lll}
\hline & $\begin{array}{l}\text { Cancer } \\
\text { Registry }\end{array}$ & $\begin{array}{l}\text { Supplementary } \\
\text { Pension Fund }\end{array}$ \\
\hline ID number* & + & + \\
Company name & & + \\
Date of starting employment & & + \\
Date of ending employment & & + \\
Industry & + & + \\
Cancer diagnosis & + & \\
Date of diagnosis & + & \\
Evidence of diagnosis & + & \\
\hline
\end{tabular}

*Includes information on date of birth and sex.

with different industries was estimated as the standardised proportional incidence ratio (SPIR), which is a measure of the proportion of sinonasal cancer in a given industry relative to the proportion of this type of cancer among all employees in Denmark after adjustment for differences in the distribution of cases over age groups (five year) and calender periods (one year). Thus a SPIR value of 100 equals the average risk of sinonasal cancer among all employees in the country. The SPIR value approximates the conventional incidence or mortality ratio (SIR; SMR) when the cancer under investigation constitutes a minor part of all the malignancies included in the study and when exposure has no effect on the risk of cancer in general. ${ }^{31}$ Exact confidence intervals $(95 \% \mathrm{CI})$ have been calculated, assuming a Poisson distribution for the observed frequency. ${ }^{32}$

\section{Results}

Table 3 gives the risks of cancer of the nasal cavity and paranasal sinuses associated with work in the major industries in Denmark. Among men employed in the main branch of community, social, and personal services, the risk was significantly below expectancy, with 34 cases of sinonasal cancer observed compared with $50 \cdot 1$ expected (SPIR $=68 ; 95 \%$ CI $=47-95$ ). Non-significant increases were observed among men in manufacturing (SPIR $=107$ ) and in trade, restaurants, and hotels (SPIR = 136). Among female employees, a strongly significant excess of six cases compared with 1.3 expected was detected in those working in agriculture, forestry, and fishing (SPIR = 
468), which was due exclusively to an excess risk in true farming (SPIR $=735 ; 95 \% \mathrm{CI}=269-1627$; see table 6). As for men, a risk above expectancy was observed for women in manufacturing (SPIR = 132); however, a marginally significant decreased risk was seen among women in trade, restaurants, and hotels (SPIR $=46$; $95 \% \mathrm{CI}=17-102$ ).

Tables 4-6 give the risks of cancer of the nasal cavity and paranasal sinuses for all subgroups of employees in manufacturing by a two digit international standard industrial classification (ISIC) code, and for selected subgroups of interest on a more detailed level (up to five digit codes). Table 4 , which covers the textile, wood, paper, and chemical industries, shows that three cases were detected among employees making leather products, including footwear, which corre- sponds to a tenfold excess risk $(\mathrm{SPIR}=1227 ; 95 \% \mathrm{CI}$ $=312-3340$ ); a further case was seen in a woman engaged in making leather products $(0 \cdot 1$ expected) but none in women making footwear $(0.2$ expected). Five male cases of sinonasal cancer were observed in wooden furniture production compared with 1.4 expected (SPIR $=360 ; 95 \% \mathrm{CI}=132-798)$; and two cases were observed among male employees manufacturing paints and lacquers compared with 0.5 expected $(\mathrm{SPIR}=401 ; 95 \% \mathrm{CI}=67-1324)$.

Table 5 shows the risk of sinonasal cancer among selected subgroups of male employees making metal, metal products, and non-metallic mineral products. A significantly increased risk was detected among men employed in the basic metal industries, with seven cases of sinonasal cancer observed compared with $2 \cdot 0$

Table 3 Risks of cancer of the nasal cavity and paranasal sinuses among male and female employees within the main branches of industry in Denmark

\begin{tabular}{|c|c|c|c|c|c|c|c|}
\hline \multirow[b]{2}{*}{ ISIC code } & \multirow[b]{2}{*}{ Industrial activity } & \multicolumn{3}{|c|}{ Male employees } & \multicolumn{3}{|c|}{ Female employees } \\
\hline & & Obs & Exp & $S P I R$ & Obs & Exp & SPIR \\
\hline $\begin{array}{l}1 \\
2 \\
3 \\
4 \\
5 \\
6 \\
7 \\
8 \\
9 \\
0\end{array}$ & $\begin{array}{l}\text { Agriculture, forestry, and fishing } \\
\text { Mining and quarrying } \\
\text { Manufacturing } \\
\text { Electricity, gas, and water supply } \\
\text { Construction } \\
\text { Trade, restaurants, and hotels } \\
\text { Transport, storage, and communication } \\
\text { Financing, insurance, and real estate } \\
\text { Community, social, and personal services } \\
\text { Type of industry undefined }\end{array}$ & $\begin{array}{r}4 \\
0 \\
70 \\
1 \\
16 \\
39 \\
17 \\
14 \\
34 \\
86\end{array}$ & $\begin{array}{r}5 \cdot 1 \\
0 \cdot 4 \\
65 \cdot 2 \\
1 \cdot 7 \\
18 \cdot 9 \\
28 \cdot 7 \\
20 \cdot 6 \\
17 \cdot 0 \\
50 \cdot 1 \\
73 \cdot 3\end{array}$ & $\begin{array}{r}79 \\
- \\
107 \\
59 \\
85 \\
136 \\
82 \\
82 \\
68^{*} \\
117\end{array}$ & $\begin{array}{r}6 \\
0 \\
18 \\
0 \\
0 \\
5 \\
3 \\
5 \\
39 \\
25\end{array}$ & $\begin{array}{r}1.3 \\
0.0 \\
13.7 \\
0.1 \\
0.6 \\
10.8 \\
3.4 \\
6.4 \\
37.0 \\
27.6\end{array}$ & $\begin{array}{c}468^{*} \\
\overline{132} \\
- \\
- \\
46 \\
87 \\
78 \\
106 \\
91\end{array}$ \\
\hline & Total & 281 & $281 \cdot 0$ & 100 & 101 & $101 \cdot 0$ & 100 \\
\hline
\end{tabular}

${ }^{*} \mathrm{p}<0 \cdot 05$. ISIC, International standard industrial code.

Table 4 Risks of cancer of the nasal cavity and paranasal sinuses among selected subgroups of male and female employees in textile, wood, paper, and chemical industries

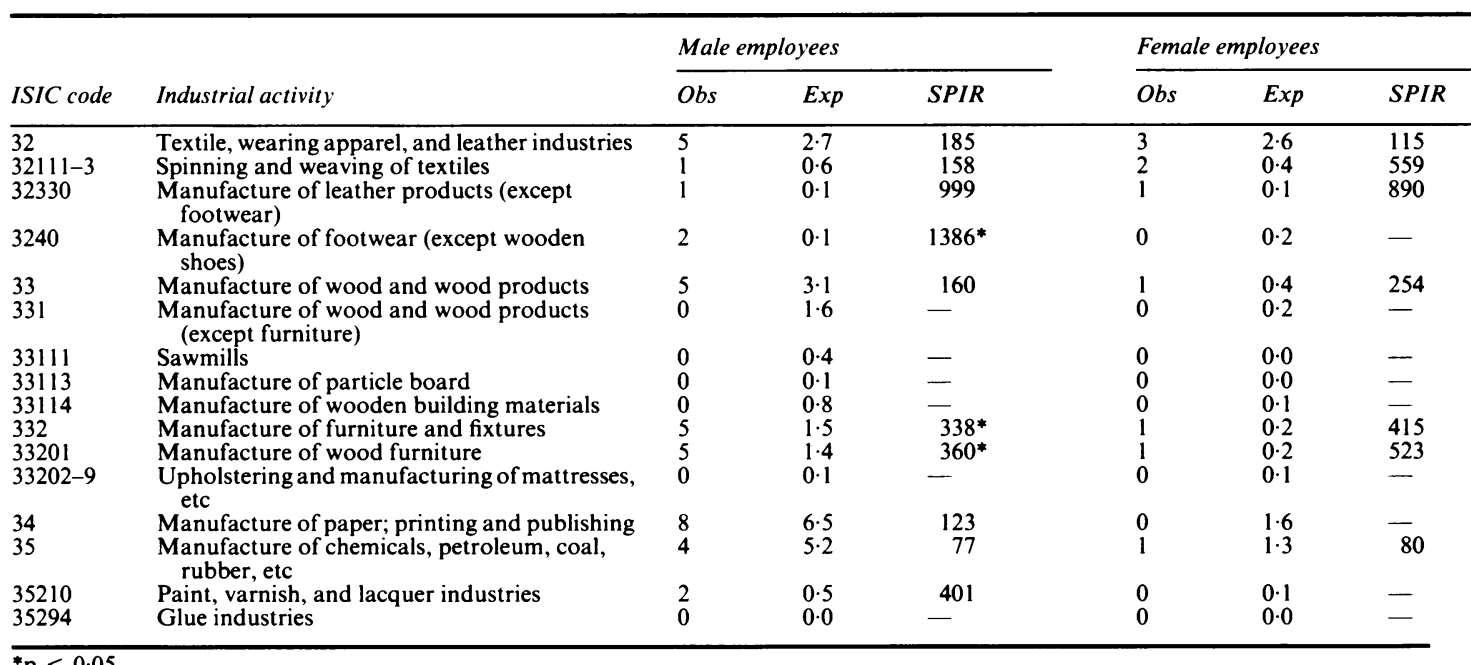

${ }^{*} \mathrm{p}<0 \cdot 05$. 
Table 5 Risks of cancer of the nasal cavity and paranasal sinuses among selected subgroups of male employees in the manufacture of non-metallic mineral products and in the metal industries

\begin{tabular}{|c|c|c|c|c|}
\hline $\begin{array}{l}\text { ISIC } \\
\text { code }\end{array}$ & Industrial activity & Obs & $\operatorname{Exp}$ & $S P I R$ \\
\hline & $\begin{array}{l}\text { Manufacture non-metallic mineral } \\
\text { products }\end{array}$ & 2 & $4 \cdot 6$ & 44 \\
\hline 37 & Basic metal industries & 7 & $2 \cdot 0$ & $351 *$ \\
\hline 371 & Basic iron and steel industries & 5 & $1 \cdot 6$ & $308^{*}$ \\
\hline 37101 & Manufacture of iron and steel & 3 & 0.5 & $562^{*}$ \\
\hline 37102 & Foundries & 2 & $1 \cdot 1$ & 184 \\
\hline 372 & Basic non-ferrous metal industries & 2 & 0.4 & 541 \\
\hline 37201 & Manufacture of metal products & $\overline{1}$ & $0 \cdot 2$ & 445 \\
\hline 37202 & Non-ferrous metal foundries & 1 & $0 \cdot \overline{1}$ & 689 \\
\hline 38 & $\begin{array}{l}\text { Manufacture of metal products, } \\
\text { machinery, and equipment }\end{array}$ & 29 & $26 \cdot 2$ & 110 \\
\hline 38190 & $\begin{array}{l}\text { Manufacture of central heating } \\
\text { containers }\end{array}$ & 1 & $0 \cdot 3$ & 329 \\
\hline 38191 & $\begin{array}{l}\text { Manufacture of metal packaging } \\
\text { (cans, containers, etc) }\end{array}$ & 3 & 0.5 & $571^{*}$ \\
\hline 38431 & Manufacture of motor vehicles & 2 & 0.4 & 462 \\
\hline 38432 & Bodywork & 2 & 0.3 & $600^{*}$ \\
\hline 38439 & $\begin{array}{l}\text { Manufacture of other parts of } \\
\text { motor vehicles }\end{array}$ & 0 & $0 \cdot 1$ & - \\
\hline 39 & Other manufacturing industries & 0 & 0.8 & - \\
\hline
\end{tabular}

expected (SPIR $=351 ; 95 \%$ CI $=154-695)$; the companies included in this industrial category are primarily engaged in the smelting and forming of iron, steel, and other metals. In addition, three cases were observed in the manufacture of metal packaging $(0.5$ expected), one in the manufacture of central heating containers ( 0.3 expected), and, most notably, four in the manufacture of motor vehicles, including bodywork, compared with 0.7 expected (SPIR $=471 ; 95 \%$ $\mathrm{CI}=150$-1137).

Not shown in the tables, but worth mentioning is one case observed among women making china and earthenware $(0.2$ expected) and one case in those engaged in painting and firing china ( 0.0 expected).

Two male and two female cases of sinonasal cancer were recognised among employees making cocoa, chocolate, and sugar confectionery compared with $0 \cdot 4$ and 0.2 cases expected, respectively (table 6 ), yielding a common SPIR value of $650(95 \% \mathrm{CI}=210-1591)$.
Table 7 Risks of cancer of the nasal cavity and paranasal sinuses among selected subgroups of male employees in construction and trade and in community and social services

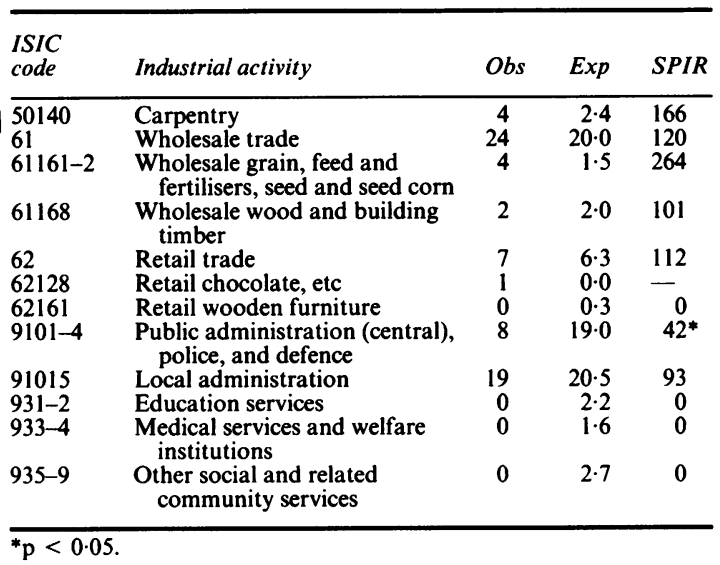

Among women, two cases were observed in canning and preserving fruits and vegetables versus 0.3 cases expected (SPIR $=778 ; 95 \% \mathrm{CI}=131-2571)$.

Table 7 gives the risks of sinonasal cancer among male employees in selected subgroups of construction and trade and of community and social services. The significantly decreased risk among men in the main branch of community and social services (table 3 ) is due to a generally low risk in most subgroups of this branch (table 7). Among male employees in public administration, police, and defence, only eight cases were observed versus $19 \cdot 0$ expected (SPIR $=42$ ). Even more striking is the absence of sinonasal cancers among men in education and medical services and other social and related institutions $(6 \cdot 5$ expected).

\section{Discussion}

This proportional incidence analysis of industrial work history and risk of cancer of the sinonasal cavities is based on 541 cases notified to the cancer

Table 6 Risks of cancer of the nasal cavity and paranasal sinuses among selected subgroups of male and female employees in agriculture and in foodstuff industries

\begin{tabular}{|c|c|c|c|c|c|c|c|}
\hline \multirow[b]{2}{*}{ ISIC code } & \multirow[b]{2}{*}{ Industrial activity } & \multicolumn{3}{|c|}{ Male employees } & \multicolumn{3}{|c|}{ Female employees } \\
\hline & & Obs & $\operatorname{Exp}$ & $S P I R$ & Obs & $\operatorname{Exp}$ & SPIR \\
\hline
\end{tabular}

${ }^{*} \mathrm{p}<0.05$. 
registry during 1970-84. Despite the limited number of cases and the large number of industrial activities tested, the results point to certain high risk occupations for this otherwise rare type of tumour. The highly significant excess risks of sinonasal cancer observed among male and female employees making footwear and other leather products and wooden furniture were expected owing to the well known carcinogenic potential of leather and wood dusts for these anatomical sites. ${ }^{3-533}$ It is, however, noteworthy that no case was detected either in the branch of forestry and logging (not shown in the tables) or among employees engaged in making wood and wood products other than furniture $(2 \cdot 1$ cases expected among men and $0 \cdot 1$ among women). In carpentry only four cases were observed compared with $2 \cdot 4$ expected.

These observations are in line with the results of most studies which have found that the risk of sinonasal cancer among woodworkers outside the furniture making industry is probably negligible. ${ }^{34}$ The most recent of these was a cohort study of workers in particle board, plywood, and formaldehyde factories and sawmills in Finland, in which no case was observed among 3805 workers who entered these industries between 1944 and $1966 .{ }^{35} \mathrm{~A}$ few studies have had results that contrast with these. In a Scandinavian case-control study exposure to softwood dust (birch included) was found to be associated with cancer of the sinonasal cavities, and most of the 13 cases included were construction and sawmill workers. ${ }^{7}$ Likewise, recent data from a Dutch study suggest a more than tenfold increased risk of adenocarcinoma of the sinonasal cavities in joinery or carpentry workers. ${ }^{36}$ These findings may indicate that other factors besides the type of wood are of importance-for example, the type of machinery used and the concentration of wood dust prevailing in the workplace (outdoor or indoor workers).

The risk of cancer of the sinonasal cavities was found to be significantly raised in all segments of the basic metal industries both in the manufacture of primary iron and steel products, consisting of all processes from smelting in blast furnaces to the semifinished stage in rolling mills and foundries (SPIR = 308 ), and in the manufacture of non-ferrous metal products, consisting of all processes from smelting, alloying and refining, rolling and drawing to founding and casting (SPIR = 541). The risk was also increased in industries fabricating metal products, machinery, and equipment (group 38) but apparently only in the subset of industries producing containers - for example, metal cans from tinplate, terne-plate or enamelled sheet metal, metal shipping containers, barrels, drums, kegs, and pails (SPIR = 571), furnaces, stoves, and other space heaters (SPIR $=329$ ). The manufacture of motor vehicles, especially bodywork $($ SPIR $=600$ ), may be included in this subset of metallic industries. Common exposures to nickel and chromium compounds may well be the explanation; however, exposures to polycyclic aromatic hydrocarbons, cutting oils, fumes, and heat occur frequently in these industries. A further evaluation of the causative agents will require a full description of the workplaces.

No association was found between cancer of the nasal cavity and paranasal sinuses and employment in petroleum and chemical industries, apart from a nonsignificant excess risk among male employees making paint, varnishes, and lacquers. The latter association was also seen in earlier studies. ${ }^{713}$

In line with earlier reports there were excess numbers of cases among men and women in the textile industry ${ }^{1819}$; however, the association observed in the present analysis was weak and based on only three cases in spinning and weaving, of which one spun and wove synthetic fibres.

Unexpected excess risks of sinonasal cancer were observed in workers of both sexes making cocoa, chocolate, and sugar confectionery. The figures are small but the excesses are significant. This finding may be linked to the excess number of female cases observed in the canning and preserving of fruits and vegetable (SPIR $=778)$ and the highly significant excess number of female cases employed in farming (SPIR = 735), not found among men in this trade. The boiling of sugar, preparation of syrup, and similar work may be the subject of further study, although no case was observed in sugar factories or refineries, either among men $(0.8$ expected) or women $(0 \cdot 1$ expected). Since these associations are based on linked material for the designated purpose of screening for occupational cancer risks, they must await confirmation from other studies.

Screening for occupational cancer risks by large scale data linkage has several limitations. In the present study occupational histories were obtained from nationwide registries and there is thus no information bias; however, misclassification may occur owing to the absence of detailed exposure information (other than company and industry) and due to the categorisation of patients according to employment held longest. Other jobs held by the patient may well be of direct importance for the occurrence of the tumour. Such unbiased misclassification will tend to bias the relative risk estimate towards 100 , which implies that true associations may be overlooked. ${ }^{37}$

Changes in risk of sinonasal cancer may also be due to a combination of social and economic factors prevailing among the employees in a given industry rather than to factors operating within the working environment. Except for the possible role of tobacco consumption on the risk of sinonasal cancer, ${ }^{181923}$ other such confounders are not described; if present 
the confounding effect of smoking on the risk of sinonasal cancer would be modest and would not explain the substantially raised risks observed in the present study. This assumption is supported by the striking absence of an upward trend in sinonasal cancer in Denmark over the past 40 years.

Information on job histories in this linkage study dates back only to 1964 , and thus the most important period for the induction of cancer of the sinonasal cavities may not be covered. It is not unreasonable to assume, however, that skilled workers tend to stay in their trades and unskilled workers seek employment in related industries, but migration between jobs would tend to dilute any influence of a given job exposure on the risk of cancer.

Finally, the insoluble problem of mass significance occurs in any large scale linkage study. Outstanding risk estimates should therefore be examined for consistency between the two sexes and in related occupations. This may be illustrated by the excess risk of sinonasal cancer observed in the manufacture of cocoa, chocolate, and sugar confectionery among men and women, supported by a similar excess risk among women in canning and preserving fruits and vegetables; or by the raised risk apparent in most industries fabricating metal containers. The results of the present study must also be compared with risk estimates derived from similar studies performed in other countries or geographical areas. ${ }^{38}$

Despite these limitations, even in a general occupational study of this sort, the predictable increased (and decreased) risks were readily apparent, and several additional risk factors were observed consistently, although these must await further confirmation. Overall, the present analysis emphasises the importance of industrial exposures in the aetiology of cancer of the nasal cavity and paranasal sinuses.

\section{References}

1 Redmond CK, Sass RE, Roush GC. Nasal cavity and paranasal sinuses. In: Schottenfeld D, Fraumeni JF Jr, eds. Cancer epidemiology and prevention. Philadelphia: WB Saunders, 1982:519-35.

2 Macbeth R. Malignant disease of the paranasal sinuses. J Laryngol 1965;79:592-612.

3 Acheson ED. Nasal cancer in the furniture and boot and shoe manufacturing industries. Prev Med 1976;5:295-315.

4 Mosbeck J, Acheson ED. Nasal cancer in furniture-makers in Denmark. Dan Med Bull 1971;18:34-5.

5 Olsen J, Sabroe S. A follow-up study of non-retired and retired members of the Danish carpenter/carbined markers' trade union. Int J Epidemiol 1979;8:375-82.

6 Brinton LA, Blot WJ, Stone BJ, Fraumeni JF Jr. A death certificate analysis of nasal cancer among furniture workers in North Carolina. Cancer Res 1977;37:3473-4.

7 Hernberg S, Westerholm P, Schultz-Larsen K, et al. Nasal and sinonasal cancer: connection with occupational exposures in Denmark, Finland and Sweden. Scand J Work Environ Health 1983;9:315-26.
8 International Agency for Research on Cancer. Monographs on the evaluation of the carcinogenic risk of chemicals to humans. Suppl 4. Chemicals, industrial processes and industries associated with cancer in humans. Lyon: IARC, 1982.

9 Enterline PE. Respiratory cancer among chromate workers. $J$ Occup Med 1974;16:523-6.

10 Hasterlik RJ, Finkel AJ, Miller CE. The cancer hazards of industrial and accidental exposure to radioactive isotopes. Ann NY Acad Sci 1964;114:823-7.

11 Wada S. Miyanishi M, Nishimoto Y, et al. Mustard gas as a cause of neoplasia in man. Lancet 1968;i:1161-3.

12 Rousch GC, Meigs JW, Kelly J, Flannery JT, Burdo H. Sinonasal cancer and occupation, a case-control study. Am J Epidemiol 1980;11:183-93.

13 Olsen JH, Jensen SP, Hink H, Faurbo K, Breum NO, Jensen OM. Occupational formaldehyde exposure and increased nasal cancer risk in man. Int $J$ Cancer 1984;34:639-44.

14 Cecchi F, Buiatti E, Kriebel D, et al. Adenocarcinoma of the nose and paranasal sinuses in shoemakers and woodworkers in the province of Florence, Italy (1963-77). Br J Ind Med 1980; 37:222-5.

15 Acheson ED, Cowdell RH, Rang EH. Nasal cancer in England and Wales: an occupational survey. Br J Ind Med 1981;38: 218-24.

16 Hueper WC. Occupational and environmental cancers of the respiratory system. Recent Results Cancer Res 1966:3:105-7.

17 Eckardt RE. Annals of industry-non-casualties of the work place. J Occup Med 1974;16:472-7.

18 Brinton LA, Blot WJ, Becker JA, et al. A case-control of cancers of the nasal cavity and the paranasal sinuses. Am J Epidemiol 1984;119:896-906.

$19 \mathrm{Ng}$ TP. A case-referent study of cancer of the nasal cavity and sinuses in Hong Kong. Int J Epidemiol 1986:15:171-5.

20 Rushton L, Alderson MR. An epidemiological survey of eight oil refineries in Britain. Br J Ind Med 1981:38:225-34.

21 Hoover R, Fraumeni JF. Cancer mortality in US counties with chemical industries. Environ Res 1975:9: 196-207.

22 Blot WJ, Brinton LA. Fraumeni JF, et al. Cancer mortality in US counties with petroleum industries. Science 1977:198:51-3.

23 Hayes RB, Raatgever JW, DeBruyn A, Gerin M. Cancer of the nasal cavity and paranasal sinuses and formaldehyde exposure. Int J Cancer 1986;37:487-92.

24 Olsen JH, Asnæs S. Formaldehyde and risk of squamous cell carcinoma of the sinonasal cavities. Br J Ind Med 1986:43: 769-74.

25 Olsen JH, Jensen OM. Occupation and risk of cancer in Denmark: an analysis of 98810 cancer cases. 1970-1979. Scand J Work Environ Health 1987;suppl 1:1-91.

26 Danish Cancer Registry. Incidence of cancer in Denmark. 1973-77. Copenhagen: Danish Cancer Society, 1982.

27 Østerlind A, Jensen OM. Evaluation of registration of cancer cases in 1977. Preliminary evaluation of registration of cancer cases by the Cancer Registry and National Patient Registry. Ugeskr Laeger 1985;147:2483-8. (In Danish.)

28 Jensen OM, Storm HH, Jensen HS. Cancer registration in Denmark and the study of multiple primary cancer 1943-80. Natl Cancer Inst Monogr 1985:68:245-51.

29 World Health Organisation. Manual of the international statistical classification of diseases, injuries, and causes of death. 7 th rev. Geneva: WHO, 1957.

30 United Nations. Indexes to the international standard industrial classification of all economic activities ( ST/STAT/SERM/Revl/ Addl ) New York: Statistical Office of the United Nations, 1968.

31 Monson RR, ed. Occupational epidemiology. Boca Raton, Fl: CRC Press, 1982.

32 Rothman KJ. Boice JD. Epidemiologic analysis with a programmable calculator. Boston: Epidemiology Resources. Inc. 1982.

33 Jensen OM. The cancer registry as a tool to detect industrial risks. Bull Cancer (Paris) 1983:70:423-8.

34 Acheson ED. Nasal cancer in furniture workers: the problem. In: 
Acheson ED, ed. The carcinogenicity and mutagenicity of wood dust. Southampton: MRC Environmental Epidemiology Unit. 1982. (Sci rep No 1.)

35 Partanen T, Kauppinen T. Nurminen M. et al. Formaldehyde exposure and respiratory and related cancers: a case-referent study among Finnish woodworkers. Scand $J$ Work Environ Health 1985:11:409-15.

36 Hayes RB, Gerin M, Raatgever JW, De Bruyn A. Wood-related ccupations, wood dust exposure, and sinonasal cancer. $A m$ Epidemiol 1986;127:569-77.

37 Tzonou A. Kaldor J, Smith PG. Day NE. Trichopoulos D. Misclassification in case-control studies with two dichotomous risk factors. Rev Epidemiol Sante Publique 1986;34:10-7.

38 Jensen OM, Lynge E. The contribution of epidemiology to the study of occupational cancer. J Cancer Res Clin Oncol 1984; 108:257-63. 